\title{
Polymer supported carbon nanotube arrays for field emission and sensor devices
}

\author{
Paul C. P. Watts, ${ }^{\text {a) }}$ Stephen M. Lyth, Ernest Mendoza, and S. Ravi P. Silva \\ Nano-Electronics Centre, Advanced Technology Institute, University of Surrey, Guildford, \\ Surrey GU2 7XH, United Kingdom
}

(Received 6 March 2006; accepted 16 July 2006; published online 8 September 2006)

\begin{abstract}
The authors report a simple method for providing a polymer support structure for carbon nanotube (CNT) arrays for device applications. This method has a twofold effect: firstly it secures the nanotubes to the substrate and secondly it significantly decreases the threshold field for field emission from 26.2 to $9.7 \mathrm{~V} / \mu \mathrm{m}$. This method ensures that the main body and tips of the CNTs are polymer-free and therefore can also be applied to CNT sensor array device fabrication. (C) 2006 American Institute of Physics. [DOI: 10.1063/1.2345615]
\end{abstract}

Aligned carbon nanotube $(\mathrm{CNT})$ arrays ${ }^{1,2}$ are attracting increased interest for sensing applications and are currently studied as platforms for a variety of sensor devices ${ }^{3-5}$ and field emission (FE) sources in flat screen displays. ${ }^{6,7}$ An underlying drawback for CNT arrays being used as sensing platforms is the fact that the nanotubes are weakly bound to the silicon substrate and are susceptible to facile detachment [Fig. 1(a): effect from scratching], which reduces performance and lifetime, when incorporated in sensor and display technologies. Recently, there has been much investigation into the possible toxicological effects of carbon nanotubes with biological systems. ${ }^{8,9}$ In the case of CNT electrophysiological sensors, ${ }^{10}$ nanotube detachment from the substrate becomes an important issue.

There are several additional issues to be tackled if CNTs are to become viable FE materials, such as improvement of turn on fields, mechanical stability, and the robustness of the substrates. Degradation of CNT arrays during FE occurs mainly due to mechanical failure at the tube-substrate contact and resistive heating. ${ }^{11}$ Plasma post-treatment with $\mathrm{O}_{2},{ }^{12}$ $\mathrm{CF}_{4},{ }^{13} \mathrm{Ar}^{14}{ }^{14}$ and $\mathrm{H}_{2}$ (Ref. 15) has been used to alter the FE properties of CNT arrays by removing surface amorphous carbon impurities, ${ }^{16,17}$ introducing defects, ${ }^{15}$ and by modifying the work function of the surface of the CNTs. ${ }^{12}$ Previous work has shown that $\mathrm{O}_{2}$ impurities etch the base of the CNTs during FE characterization due to large contact resistances between the substrate and CNTs, resulting in an increase in threshold field. ${ }^{18}$

Our previous work has revealed that polystyrene (PS)-multiwall carbon nanotube (MWNT) composite films exhibit excellent FE properties (low threshold fields: $1.6 \mathrm{~V} / \mu \mathrm{m})$ from the fracture surface at relatively low CNT concentrations (ca. 12 wt. \%). ${ }^{19,20}$ Further investigation of the fracture surface by scanning electron microscopy (SEM) shows that after the MWNTs have been pulled out of the PS matrix, there remains polymer attached to the nanotube surface, indicating good adhesion between the tubes and polymer [Fig. 1(b)].

We have developed a facile method for the fabrication of a thin PS support, which holds the tubes securely to the substrate surface while ensuring that the nanotubes are free

\footnotetext{
a) Author to whom correspondence should be addressed; electronic mail:
} p.watts@surrey.ac.uk of polymer and available for FE and chemical/biological functionalization. We demonstrate that the FE properties are noticeably enhanced after the polymer layer has been fabricated due to the oxygen plasma treatment step. Threshold fields decrease from 26.2 to $9.7 \mathrm{~V} / \mu \mathrm{m}$ for MWNT arrays without and with the PS support, respectively.

The MWNT arrays were grown on highly doped silicon substrates using plasma enhanced chemical vapor deposition of acetylene over an iron catalyst. An iron film $(20 \mathrm{~nm})$ was sputtered onto the silicon wafer and heated to $650{ }^{\circ} \mathrm{C}$ for $20 \mathrm{~min}$ in vacuum, resulting in $\mathrm{Fe}$ islands between 50 and $100 \mathrm{~nm}$ in diameter. ${ }^{2}$ During the growth process the substrate was maintained at $650{ }^{\circ} \mathrm{C}$ and acetylene was introduced to the chamber at a concentration of $5.0 \%$ with $\mathrm{N}_{2}$ as the carrier gas. The length of the as-grown MWNTs (diameter of ca. $50 \mathrm{~nm}$ ) depends on growth time. Typically, the length of the MWNTs for a $15 \mathrm{~min}$ growth process is $1-2 \mu \mathrm{m}$, but we have achieved lengths of $>10 \mu \mathrm{m}$.

The MWNT array was first immersed in a PS (Aldrich, $\mathrm{UK}, \mathrm{Mn}=280000) /$ toluene $\left(0.03\right.$ wt. \%) solution at $40{ }^{\circ} \mathrm{C}$ for $24 \mathrm{~h}$ in order to increase the absorption of the solution into the arrays. It was then removed from the solution and spin coated at $6000 \mathrm{rpm}$ for $30 \mathrm{~s}$. The array was heated to just above the glass transition temperature of PS, $120^{\circ} \mathrm{C}\left(T_{g}\right.$ of $\mathrm{PS}=110^{\circ} \mathrm{C}$ ), in order for the polymer chains to slide

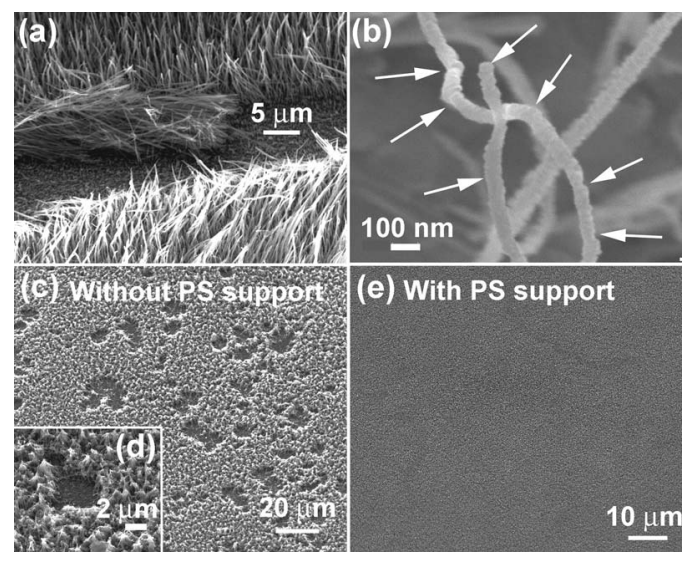

FIG. 1. (a) CNT detachment after the array was scratched. (b) SEM image of the fracture surface of a PS/MWNT composite film. SEM of the MWNT arrays after sonication (c) with a PS support and (e) and without a PS support. Insert (d): magnification of destructed region. 

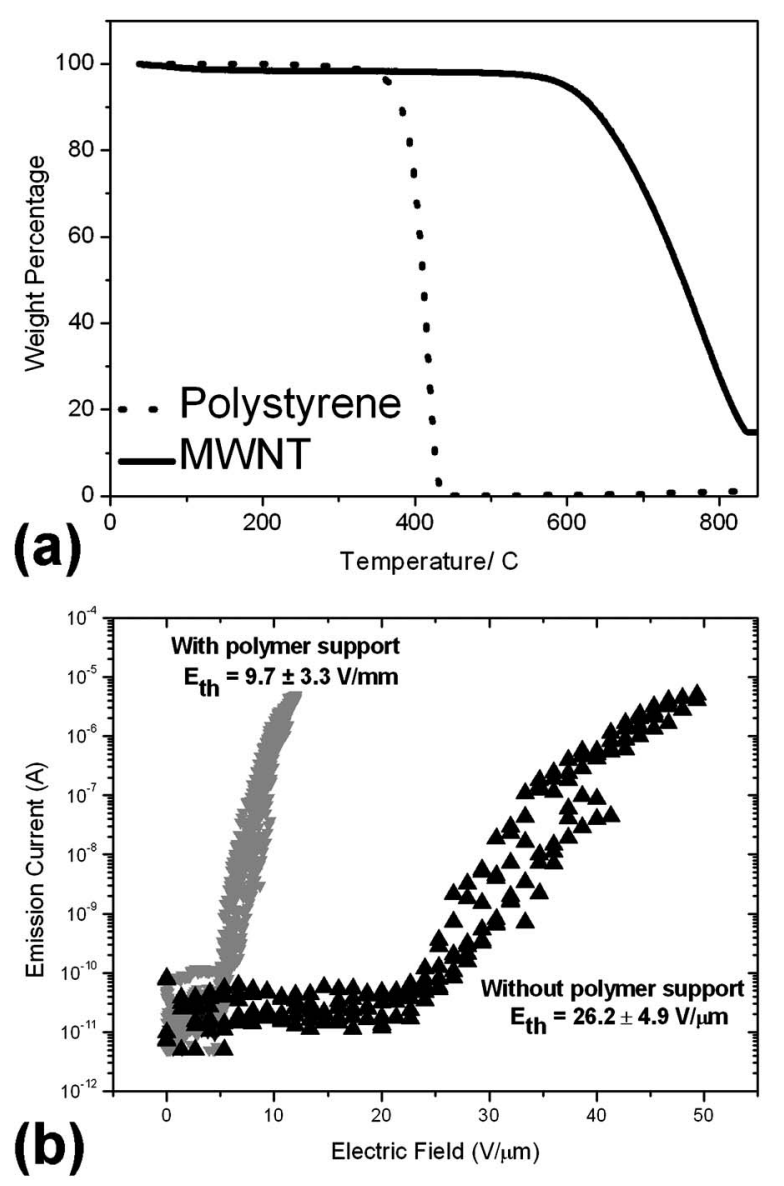

FIG. 2. (a) TGA for PS and MWNTs. (b) FE from the MWNT array with and without the polymer support.

down onto the silicon substrate. A layer of PS remained on the tube tips; therefore oxygen plasma etching [Plasma-Preen I, $180 \mathrm{~W}, 60 \mathrm{~s}$, and $\mathrm{O}_{2}$ flow of $2.5 \mathrm{SCCM}$ (SCCM denotes cubic centimeter per minute at STP)] was carried out to oxidize the PS and expose the tube ends for functionalization. The resulting MWNT array with PS support structure and exposed tube tips were characterized by SEM (FEI Quanta 200F).

The samples were subjected to field emission characterization at $10^{-6}$ mbar. A $5 \mathrm{~mm}$ diameter spherical stainless steel anode was placed typically $70 \mu \mathrm{m}$ above the substrate. The threshold field was arbitrarily taken to be the macroscopic electric field at which an emission current of $1 \mathrm{nA}$ was detected. Six different sites were probed on each sample and the current was cycled up and down six times at each of these sites to obtain average threshold field.

PS was chosen as the polymer material for the support due to its ease of handling and low cost. In the absence of covalent bonding between nanotubes and a PS matrix, the nonbonded interactions consist of electrostatic and van der Waals interactions. ${ }^{21}$ In a previous report on molecular mechanics of a CNT pullout simulation the authors calculated that the interfacial shear stress of the CNT-PS system was ca. $160 \mathrm{MPa} .{ }^{21}$ Figure 1(b) shows a SEM of a fracture surface of a MWNT-PS composite showing that the nanotubes, which are pulled out of the PS matrix, are coated with PS (arrows). This indicates that the van der Waals and electrostatic interactions between the nanotubes and polymer chains are stronger than the chain-chain nonbond interactions, suggesting PS as an appropriate reinforcing material for CNT arrays. as an appropriate reinforcing material for CNT arrays. gen plasma treatment, corresponding to a 63\% improvement.
Downloaded 30 Mar 2009 to 131.227.178.132. Redistribution subject to AIP license or copyright; see http://apl.aip.org/apl/copyright.jsp

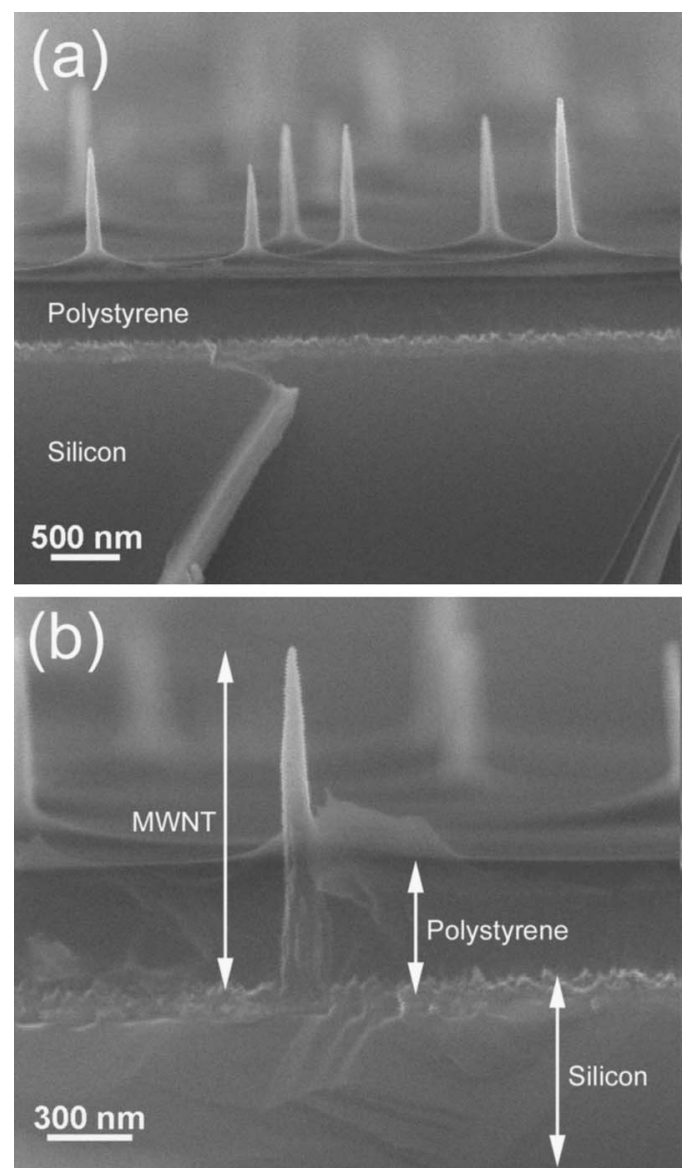

FIG. 3. (a) SEM of the fracture edge of a PS supported MWNTs array. (b) shows the tube attached to the silicon substrate, embedded in $400 \mathrm{~nm}$ of the PS support structure.

MWNTs are more oxidatively stable than PS, as shown by thermogravimetric analysis (TGA, Perkin Elmer 7) [Fig. 2(a)]. PS oxidizes in air at ca. $380{ }^{\circ} \mathrm{C}$ whereas MWNTs oxidize at ca. $625^{\circ} \mathrm{C}$, demonstrating that MWNTs are more resistant to oxidation than PS. After heating the array to $120^{\circ} \mathrm{C}$, much of the PS has sunk to the substrate surface affording a thin PS support ca. $400 \mathrm{~nm}$. In addition, there remains a thin coating (ca. $>5 \mathrm{~nm}$ ) of PS on the section of nanotubes which is not embedded in the support. During the plasma etching the PS is preferentially oxidized due to its lower oxidative stability compared to the MWNTs and the tube ends become exposed. The thin support structure is also subject to oxidation from the plasma but only ca. 5-10 nm; therefore the bulk of the support remains.

Figure 3(a) shows a SEM image of a fractured edge of an array with a PS support structure. The tubes are ca. $2 \mu \mathrm{m}$ in length and have an intertube spacing of ca. $3 \mu \mathrm{m}$. The PS support is clearly evident and the thickness is ca. $400 \mathrm{~nm}$. Figure 3(b) is a higher magnification image showing that the MWNT is attached to the silicon substrate and that the PS support layer has embedded the end of the tube attached to the substrate.

Figure 2(b) shows typical field emission current versus applied electric field characteristics of the MWNT arrays before and after PS coating and oxygen plasma treatment. The threshold field is reduced from 26.2 to $9.7 \mathrm{~V} / \mu \mathrm{m}$ after oxy- 
The high threshold field before treatment is attributed to a layer of insulating amorphous carbon coating the CNTs, leading to inefficient electron emission. $\mathrm{O}_{2}$ plasma treatment removes the insulating amorphous layer ${ }^{16,17}$ as well as increases the number of defects in the CNT structure, resulting in improved emission characteristics.

In order to gain some information regarding the mechanical nature of the PS support we carried out ultrasonication treatment on the arrays. Figure 1 shows the effect after ultrasonication an array without $[(\mathrm{c})$ and (d)] and with (e) a PS support. Figure 1(c) clearly shows destructed patches on the array. Closer investigation [Fig. 1(d)) reveals that the tubes completely detached from the arrays in the patch regions. PS supported arrays show no sign of destructed regions or nanotube detachment, indicating that the PS support protects against nanotube detachment during ultrasonication treatment.

We demonstrate a facile method for providing CNT arrays with a PS support structure of ca. $400 \mathrm{~nm}$ thickness, which secures the tubes effectively to the substrate and subsequent $\mathrm{O}_{2}$ plasma treatment ensures that the tube ends are without a polymer. A decrease in threshold field from 26.2 to 9.7 was recorded for the arrays with the PS support. Ultrasonication treatment of the arrays with and without a PS support reveals that the support protects against CNT detachment. This method for providing CNT arrays with a support structure noticeably enhances FE properties while protecting against CNT detachment, hence dramatically improving the lifetime of the array during FE. These polymer supported arrays can also be applied to sensor technologies by functionalization with active sensing materials.

The authors would like to thank the EPSRC (Grant No. RB3553) (U.K.) for funding this work.
${ }^{1}$ Z. F. Ren, Z. P. Huang, J. W. Xu, J. H. Wang, P. Bush, M. P. Siegal, and P. N. Provencio, Science 282, 1105 (1998).

${ }^{2}$ E. Mendoza, S. J. Henley, C. H. P. Poa, G. Y. Chen, C. E. Giusca, A. Adikaari, J. D. Carey, and S. R. P. Silva, Sens. Actuators B 109, 75 (2005).

${ }^{3}$ K. H. An, S. Y. Jeong, H. R. Hwang, and Y. H. Lee, Adv. Mater. (Weinheim, Ger.) 16, 1005 (2004).

${ }^{4}$ M. Gao, L. M. Dai, and G. G. Wallace, Electroanalysis 15, 1089 (2003).

${ }^{5}$ J. Li, H. T. Ng, A. Cassell, W. Fan, H. Chen, Q. Ye, J. Koehne, J. Han, and M. Meyyappan, Nano Lett. 3, 597 (2003).

${ }^{6}$ W. A. Deheer, A. Chatelain, and D. Ugarte, Science 270, 1179 (1995).

${ }^{7}$ Y. Saito, S. Uemura, and K. Hamaguchi, Jpn. J. Appl. Phys., Part 2 37, L346 (1998).

${ }^{8}$ C. M. Sayes, F. Liang, J. L. Hudson, J. Mendez, W. Guo, J. M. Beach, V. C. Moore, C. D. Doyle, J. L. West, W. E. Billups, K. D. Ausman, and V. L. Colvin, Toxicol. Lett. 161, 135 (2006).

${ }^{9}$ A. A. Shvedova, V. Castranova, E. R. Kisin, D. Schwegler-Berry, A. R. Murray, V. Z. Gandelsman, A. Maynard, and P. Baron, J. Toxicol. Environ. Health 66, 1909 (2003).

${ }^{10}$ G. Ruffini, S. Dunne, E. Farres, J. Marco, C. Ray, E. Mendoza, R. Silva, and C. Grau, Proceedings of Eurosensors XIX Barcelona, Spain, 2005, http://arxiv.org/abs/physics/0510145 [Sens. Actuators].

${ }^{11}$ J. M. Bonard, C. Klinke, K. A. Dean, and B. F. Coll, Phys. Rev. B 67, 115406 (2003).

${ }^{12}$ Z. Chen, D. den Engelsen, P. K. Bachmann, V. van Elsbergen, I. Koehler, J. Merikhi, and D. U. Wiechert, Appl. Phys. Lett. 87, 243104 (2005).

${ }^{13}$ Y. W. Zhu, F. C. Cheong, T. Yu, X. J. Xu, C. T. Lim, J. T. L. Thong, Z. X. Shen, C. K. Ong, Y. J. Liu, A. T. S. Wee, and C. H. Sow, Carbon 43, 395 (2005).

${ }^{14}$ K. S. Ahn, J. S. Kim, C. O. Kim, and J. P. Hong, Carbon 41, 2481 (2003).

${ }^{15}$ C. Y. Zhi, X. D. Bai, and E. G. Wang, Appl. Phys. Lett. 81, 1690 (2002).

${ }^{16}$ Chuan-Ping Juan, C.-C. Tsai, Kuei-Hsien Chen, Li-Chyong Chen, and Huang-Chung Cheung, Jpn. J. Appl. Phys., Part 1 44, 8231 (2005).

${ }^{17}$ K. Yu, Z. Q. Zhu, M. Xu, Q. Li, and W. Lu, Chem. Phys. Lett. 373, 109 (2003).

${ }^{18}$ J. H. Han, S. H. Lee, A. S. Berdinsky, Y. W. Kim, J. B. Yoo, C. Y. Park, J. J. Choi, T. Jung, I. T. Han, and J. M. Kim, Diamond Relat. Mater. 14, 1891 (2005).

${ }^{19}$ C. H. Poa, S. R. P. Silva, P. C. P. Watts, W. K. Hsu, H. W. Kroto, and D. R. M. Walton, Appl. Phys. Lett. 80, 3189 (2002).

${ }^{20}$ C. H. P. Poa, R. C. Smith, S. R. P. Silva, P. C. P. Watts, W. K. Hsu, H. W. Kroto, and D. R. M. Walton, J. Vac. Sci. Technol. B 21, 1715 (2003).

${ }^{21}$ K. Liao and S. Li, Appl. Phys. Lett. 79, 4225 (2001). 